\title{
REDUÇÃO FOLIAR EM MINIESTACAS E MICROESTACAS DE CLONES HÍBRIDOS DE Eucalyptus globulus ${ }^{1}$
}

\author{
Anne Caroline Guieiro Correia ${ }^{2}$, Aloisio Xavier ${ }^{3}$, Poliana Coqueiro Dias ${ }^{4}$, Miranda Titon $^{5}$ e Reynaldo \\ Campos Santana ${ }^{6}$
}

\begin{abstract}
RESUMO - O objetivo deste estudo foi avaliar o efeito da redução foliar no enraizamento de dois tipos (apicais e intermediárias) de miniestacas e microestacas de quatro clones híbridos de Eucalyptus globulus. Foram realizadas avaliações quanto ao percentual de sobrevivência, raízes emitidas na extremidade inferior do tubete, enraizamento, altura, diâmetro do colo e massa seca da parte aérea e da raiz. Aos 90 dias de idade, pôde-se concluir que as estacas apicais sem e com redução foliar foram superiores às intermediárias e os clones se comportaram de maneira diferenciada em relação ao enraizamento das miniestacas e microestacas. A propagação vegetativa por estacas apicais sem redução foliar pode ser recomendada para a produção de mudas de Eucalyptus urophylla x E. globuluse de Eucalyptus grandis x E. globulus.
\end{abstract}

Palavras-chave: Propagação vegetativa; Miniestaquia; Microestaquia.

\section{REDUCTION IN LEAF OF MINI-CUTTINGS AND MICRO-CUTTINGS OF HYBRID CLONES OF Eucalyptus globulus}

\begin{abstract}
The objective of this study was to evaluate the effect of leaf reduction in the rooting of two types of mini-cuttings and micro-cuttings (apical and intermediate) of four hybrid clones of Eucalyptus globulus. Evaluations were performed on the percentage of survival, roots at the lower end of the tube, rooting, height, stem diameter, dry weight of shoot and root. At 90 days, it can be concluded that the apical cuttings with and without leaf reduction were higher than the intermediate cuttings, besides each clone behaved differently in relation to the rooting of mini-cuttungs and micro-cuttings. Vegetative propagation by apical cuttings without leaf reduction can be recommended for the production of seedlings of Eucalyptus urophylla $x \boldsymbol{E}$. globulus and Eucalyptus grandis $x$ E. globulus.
\end{abstract}

Keywords: Vegetative propagation; Mini-cuttungs; Micro-cuttings.

\section{INTRODUÇÃO}

O Eucalyptus globulus e seus híbridos têm-se mostrado uma das espécies recalcitrantes ao enraizamento de estacas em razão da variabilidade da habilidade rizogênica dos clones, bem como pela redução do potencial de enraizamento com o envelhecimento ontogenético das plantas-matrizes (WATT et al., 2003).
Atualmente, essa espécie e seus híbridos têm sido alvos de grande interesse da indústria de papel e celulose por apresentarem características tecnológicas da madeira, como maior rendimento em celulose e menor teor de lignina, tornando-o muito atrativo para tal objetivo (CARDOSO, 2002; PINTO, 2007; XAVIER et al., 2007; ALFENAS et al., 2009).

\footnotetext{
${ }^{1}$ Recebido em 13.03.2013 aceito para publicação em 09.12.2014.

${ }^{2}$ Universidade Federal de Viçosa, Programa de Pós-Graduação em Ciência Florestal, Viçosa, MG - Brasil. E-mail: $<$ aguieirocorreia@yahoo.com.br>.

${ }^{3}$ Universidade Federal de Viçosa, Centro de Ciências Agrárias, Departamento de Engenharia Florestal, Viçosa, MG - Brasil. E-mail: <xavier@ufv.br>.

${ }^{4}$ Universidade Federal Rural do Semi-Árido, Departamento de Ciência Vegetal, Mossoró, RN - Brasil. E-mail: <policoqueiro@yahoo.com.br>.

${ }^{5}$ Universidade Federal dos Vales do Jequitinhonha e Mucuri, Campus JK, UFVJM, Diamantina, Minas Gerais - Brasil. E-mail: $<$ titonmiranda@yahoo.com.br>.

${ }^{6}$ Universidade Federal dos Vales do Jequitinhonha e Mucuri, Faculdade de Ciências Agrárias, Departamento de Engenharia Florestal, Diamantina, MG - Brasil. E-mail: <silviculturaufvjm@yahoo.com.br>.
}

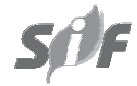

Revista Árvore, Viçosa-MG, v.39, n.2, p.295-304, 2015

http://dx.doi.org/10.1590/0100-67622015000200009 
Entre as diversas técnicas de propagação vegetativa, o aprimoramento no enraizamento de estacas de Eucalyptus tem sido alcançado com o desenvolvimento de técnicas como a miniestaquia (XAVIER; WENDLING, 1998; WENDLING et al., 2000; HIGASHI et al., 2000) e a micropropagação, aliada à microestaquia (ASSIS et al., 1992; XAVIER; COMÉRIO, 1996; TITON, 2001), que possibilitaram consideráveis ganhos, principalmente quanto ao aumento das taxas e qualidade de enraizamento e redução do tempo, para a formação da muda.

O enraizamento de estacas pode ser influenciado pela presença de gemas e, ou, folhas e pelo período de coleta das estacas (HARTAMANN et al., 2011), injúrias, balanço hormonal, constituição genética, presença de inibidores e condições nutricionais e hídricas da planta doadora de propágulos ( ASSIS et al., 2004; ALFENAS et al., 2009), além de ser fortemente influenciado pela maturação/juvelilidade dos propágulos e pelas condições ambientais de enraizamento das estacas (WENDLING et al., 2000; XAVIER, 2002).

Nos viveiros de mudas clonais, é comum a utilização de miniestacas com tamanho entre 4 e $8 \mathrm{~cm}$, com pelo menos dois pares de folhas (ALFENAS et al., 2009). A presença das folhas é essencial para o enraizamento das estacas, pois os produtos da fotossíntese proporcionam acúmulo de carboidratos, os quais favorecem o crescimento de raízes (HARTMANN; KESTER, 1975). Entretanto, para evitar o efeito "guardachuva", que pode reduzir a eficiência da irrigação, o excesso de transpiração e o recurvamento das estacas, Alfenas et al. (2009) recomendaram reduzir em um terço a lâmina foliar da miniestaca, e Xavier (2002) recomendou reduzir em $50 \%$ a área foliar.

De acordo com Santana et al. (2010), a técnica de redução foliar em miniestacas é praticamente a mesma que se utilizava em produção de mudas por macroestacas nas décadas de 1980 e 1990 , apesar de o propágulo vegetativo da miniestaca ser menor e mais juvenil, comparativamente ao da macroestaquia, além de os sistemas de irrigação terem evoluído muito nos últimos anos e, ainda, são poucos os trabalhos que tratam do efeito da redução da área foliar no enraizamento de estacas de clones de eucalyptus. Dessa forma, estudos que abordem o efeito da redução sobre o enraizamento de miniestacas são importantes para agregar maior conhecimento à propagação via miniestaquia, principalmente de espécies recalcitrantes, como clones híbridos de E. globulus.

Revista Árvore, Viçosa-MG, v.39, n.2, p.295-304, 2015
Nesse contexto, este estudo teve por objetivo avaliar a influência da redução da área foliar em miniestacas e microestacas no enraizamento e crescimento de mudas de clones híbridos de Eucalyptus globulus.

\section{MATERIAL E MÉTODOS}

\subsection{Material experimental}

Foram utilizados dois clones de Eucalyptus urophylla x E. globulus (C04 e C16) e dois clones de Eucalyptus grandis x E. globulus (C26 e C30), oriundos da empresa Cenibra S.A.

As mudas micropropagadas, utilizadas como material experimental, foram obtidas no Laboratório de Cultura de Tecidos II do Instituto de Biotecnologia Aplicada à Agropecuária (Bioagro) e as miniestacas, obtidas no Viveiro de Pesquisas Florestais do Departamento de Engenharia Florestal, ambos pertencentes à Universidade Federal de Viçosa (UFV), em Viçosa, MG.

\subsection{Formação dos jardins clonais}

Os jardins clonais foram estabelecidos, a partir de material vegetativo de microestacas e miniestacas, no Viveiro de Pesquisas Florestais do Departamento de Engenharia Florestal da Universidade Federal de Viçosa (UFV).

Conforme as técnicas de miniestaquia e microestaquia descritas em Alfenas et al. (2009) e Xavier et al. (2009), o jardim clonal foi constituído de minicepas e microcepas plantadas sob um mesmo sistema semi-hidropônico de canaletão de areia, em casa de vegetação com as laterais abertas, sendo a cobertura de plástico transparente de polietileno.

O microjardim clonal foi formado por mudas provenientes de material micropropagado pela proliferação de gemas axilares, conforme protocolo definido por Borges et al. (2011). A aclimatização e posterior formação das microestacas foram realizadas de acordo com metodologia descrita por Oliveira et al. (2012).

O minijardim clonal foi constituído de minicepas, obtidas pelo enraizamento de miniestacas, oriundas das brotações de plantas propagadas pelo método da miniestaquia. As miniestacas enraizadas foram transplantadas para o minijardim clonal, no espaçamento de $10 \mathrm{~cm} \mathrm{x} 10 \mathrm{~cm}$, e, ao atingirem cerca de $10 \mathrm{~cm} \mathrm{de}$ tamanho, tiveram seus ápices podados. 
O sistema de manejo e nutrição foi idêntico nas minicepas e microcepas, utilizando-se o mesmo canaletão de areia para formar o mini e microjardim clonal, sendo, portanto, seguindo o mesmo padrão de condução para ambos.

O sistema de fertirrigação adotado consistiu no fornecimento às plantas de solução nutritiva por gotejamento, distribuída quatro vezes ao dia, numa vazão total diária de $4 \mathrm{~L} \mathrm{~m}^{-2}$. A solução nutritiva foi composta de nitrato de cálcio $\left(0,920 \mathrm{~g} \mathrm{~L}^{-1}\right)$, cloreto de potássio $\left(0,240 \mathrm{~g} \mathrm{~L}^{-1}\right)$, nitrato de potássio $\left(0,140 \mathrm{~g} \mathrm{~L}^{-1}\right)$, monoamônio fosfato $\left(0,096 \mathrm{~g} \mathrm{~L}^{-1}\right)$, sulfato de magnésio $\left(0,364 \mathrm{~g} \mathrm{~L}^{-1}\right)$, hidroferro $\left(0,040 \mathrm{~g} \mathrm{~L}^{-1}\right)$, ácido bórico $(2,800$ $\left.\mathrm{mg} \mathrm{L}^{-1}\right)$, sulfato de zinco $\left(0,480 \mathrm{mg} \mathrm{L}^{-1}\right)$, sulfato de manganês (1,120 $\left.\mathrm{mg} \mathrm{L}^{-1}\right)$, sulfato de cobre $\left(0,100 \mathrm{mg} \mathrm{L}^{-1}\right)$ e molibdato de sódio $\left(0,040 \mathrm{mg} \mathrm{L}^{-1}\right)$. A condutividade elétrica da solução nutritiva foi mantida em $2,0 \mathrm{mS} \mathrm{m}^{-2}$ a $25^{\circ} \mathrm{C}$.

\subsection{Obtenção, preparo e estaqueamento das miniestacas e microestacas}

Miniestacas e microestacas apicais e intermediárias (Figura 1) foram coletadas no minijardim e microjardim clonal e acondicionadas em caixas de isopor contendo água, visando manter as condições de vigor e turgescência do material vegetativo. As miniestacas e microestacas apicais foram preparadas com tamanho de $10 \mathrm{~cm}$, contendo

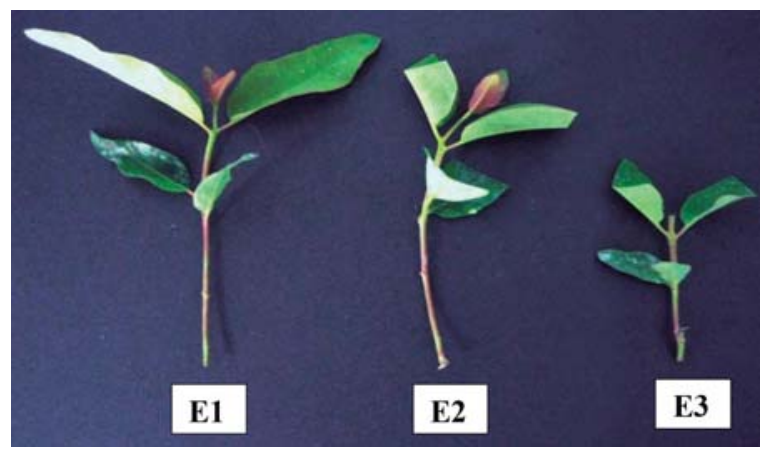

Figura 1 - Estaca apical sem redução foliar(E1), estaca apical com folha reduzida à metade de sua dimensão original (E2) e estaca intermediária com folha reduzida à metade de sua dimensão original (E3), de clone híbrido de Eucalyptus grandis x Eucalyptus globulus, usadas como padrão neste estudo.

Figure 1 - Cutting apical leaf without reduction (A), apical leaf cutting reduced to half its original size $(B)$ and intermediate cutting with leaf reduced to half its original size (C) of clone hybrid of Eucalyptus grandis $x$ Eucalyptus globulus, used as standard in this study. de dois a três pares de folhas sem redução foliar e com redução dos pares de folhas à metade de sua dimensão original. As intermediárias, por sua vez, foram confeccionadas medindo $5 \mathrm{~cm}$, com um par de folhas reduzidas à metade de sua dimensão original.

Após a confecção das miniestacas e microestacas, elas foram estaqueadas em tubetes de polipropileno com capacidade para $55 \mathrm{~cm}^{3}$ de uma mistura de $50 \%$ Bioplant ${ }^{\circledR}+50 \%$ vermiculita. A nutrição mineral de base utilizada no substrato foi composta de superfosfato simples $\left(8,00 \mathrm{~kg} \mathrm{~m}^{-3}\right)$, sulfato de amônio $\left(0,69 \mathrm{~kg} \mathrm{~m}^{-3}\right)$, cloreto de potássio $\left(0,21 \mathrm{~kg} \mathrm{~m}^{-3}\right)$, sulfato de zinco $\left(13,9 \mathrm{~g} \mathrm{~m}^{-3}\right)$, sulfato de cobre $\left(13,9 \mathrm{~g} \mathrm{~m}^{-3}\right)$, sulfato de manganês $\left(13,9 \mathrm{~g} \mathrm{~m}^{-3}\right)$ e ácido bórico $\left(27,8 \mathrm{~g} \mathrm{~m}^{-3}\right)$.

\subsection{Avaliações experimentais}

Utilizou-se um arranjo fatorial $4 \times 3 \times 2$ constituído de quatro clones (C04, C16, C26 e C30), três tipos de estacas $(\mathrm{E} 1$ = apical sem redução foliar; E2 = apical com folha reduzida à metade de sua dimensão original; e E3 = intermediária com folha reduzida à metade de sua dimensão original) e duas técnicas de propagação vegetativa (miniestaquia e microestaquia), disposto em delineamento experimental de blocos ao acaso, com quatro repetições e parcela composta de oito miniestacas/ microestacas por repetição.

O tempo de permanência das microestacas e miniestacas em casa de vegetação climatizada (umidade relativa do ar $\geq 80 \%$ e temperatura entre 20 e $30^{\circ} \mathrm{C}$ ) foi de 30 dias, sendo posteriormente aclimatadas em casa de sombra com $50 \%$ de sombreamento durante 10 dias e transferidas para área de pleno sol até completarem 90 dias de idade. Realizou-se uma adubação de cobertura, aplicando $2 \mathrm{~mL}$ por muda de fosfato monoamônico $\left(2,0 \mathrm{~g} \mathrm{~L}^{-1}\right)$, na saída da casa de vegetação. Na saída da casa de sombra, foram aplicados $5 \mathrm{~mL}$ por muda do formulado NPK (10-05-30) $\left(6 \mathrm{~g} \mathrm{~L}^{-1}\right)$. A aplicação da adubação de cobertura foi feita por meio de uma

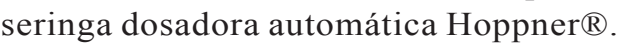

As características avaliadas foram a porcentagem de sobrevivência e a porcentagem de miniestacas e microestacas com raízes observadas na extremidade inferior do tubete na saída da casa de vegetação (30 dias) e na saída da casa de sombra (40 dias). Após 90 dias, foram avaliados a porcentagem de enraizamento, o número de raízes por miniestaca ou microestaca enraizada, altura, o diâmetro do colo e a massa de matéria seca

Revista Árvore, Viçosa-MG, v.39, n.2, p.295-304, 2015 
da parte aérea e sistema radicular, obtidas por secagem em estufa a $65^{\circ} \mathrm{C}$ até peso constante das miniestacas e microestacas.

Para efeito das avaliações, foram consideradas enraizadas e vivas as miniestacas e microestacas com raízes superiores ou iguais a $0,5 \mathrm{~cm}$ e com emissão de brotações e, para a contagem do número de raízes, foram consideradas as raízes emitidas diretamente da base das miniestacas ou microestacas.

Os dados foram submetidos à análise de variância, sendo as médias dos tratamentos comparadas pelo teste de Tukey a 5\% de probabilidade. As análises estatísticas foram realizadas no Programa STATISTICA 7 (Stasoft Inc.).

\section{RESULTADOS}

Com base nos resultados apresentados na Tabela 1 , observaram-se valores de até $100 \%$ de sobrevivência na saída da casa de vegetação e de $96,9 \%$ na saída da casa de sombra, sendo os menores valores dessa característica encontrados no clone C04, tanto na saída da casa de vegetação $(28,1 \%)$ quanto na casa de sombra (25\%). O clone C04 ainda apresentou diferenças de respostas quanto à sobrevivência entre as miniestacas e microestacas apicais sem redução foliar.

Para a característica raízes observadas na extremidade inferior do tubete, as microestacas sem redução foliar foram superiores às miniestacas de todos os clones estudados na saída da casa de vegetação e do clone C04 na saída da casa de sombra. Os clones de Eucalyptus urophylla x E. globulus e de Eucalyptus grandis $\mathrm{x}$ E. globulus apresentaram valores de raízes observadas na extremidade inferior do tubete variando entre $9,4 \%$ e $58,3 \%$ na saída da casa de vegetação e de $16,6 \%$ a $87,5 \%$ na saída da casa de sombra, conforme o tipo de estaca utilizado. Vale salientar que esse parâmetro tem sido muito utilizado pelas empresas florestais como indicador prático para identificar as miniestacas ou microestacas enraizadas e aptas a serem transferidas para a área de crescimento a pleno sol.

Em relação aos tipos de estacas, notou-se que não houve efeito dos tipos de estacas dos clones C26 e C30 sobre o parâmetro sobrevivência na saída da casa de vegetação, entretanto, na saída da casa de sombra, para essa mesma característica, os diferentes tipos de estacas se comportaram de maneira distinta para cada clone estudado. Independentemente da técnica de propagação, em geral as estacas intermediárias apresentaram os menores valores para a característica raízes observadas na extremidade inferior do tubete na saída da casa de vegetação e casa de sombra.

Ao analisar os resultados de enraizamento das miniestacas e microestacas aos 90 dias de idade (Tabela 2), notou-se que as miniestacas e microestacas apicais sem redução foliar apresentaram valores de 15,6 a 84,4\% e de $71,9 \%$ a $93,8 \%$, respectivamente, entre os clones. Nas miniestacas apicais com folha reduzida à metade de sua dimensão original, os índices de enraizamento variaram de $54,2 \%$ a $81,3 \%$ e nas microestacas, de $65,6 \%$ a $84,4 \%$. Já nas miniestacas intermediárias com folha reduzida à metade de sua dimensão original o enraizamento variou de $25,0 \%$ a $79,2 \%$ e nas microestacas, de $56,3 \%$ a $68,8 \%$. Não foi constatada diferença entre as técnicas de propagação utilizadas, exceto do clone $\mathrm{C} 04$, em que as microestacas foram superiores às miniestacas apicais sem redução foliar e intermediárias.

Em relação ao número de raízes, as microestacas de todos os clones avaliados, em geral, apresentaram valores superiores às miniestacas. As estacas intermediárias com folha reduzida à metade de sua dimensão original, quando comparadas aos outros tipos de estacas utilizados, obtiveram os menores valores dessa característica nos clones C16 e C30. Nos clones C04 e C26, não houve diferença entre os tipos de estacas utilizadas.

As características altura e diâmetro do colo das mudas não foram influenciadas pelo método de propagação (miniestaquia e microestaquia) dos clones estudados; no entanto, todas as miniestacas e microestacas intermediárias, com folha reduzida à metade de sua dimensão original, obtiveram menores valores de altura, em comparação com os outros tipos de estacas. As estacas apicais apresentam maior predisposição ao enraizamento em comparação com as intermediárias, em razão da maior juvenilidade desses propágulos, havendo, portanto, formação mais rápida de raízes com o sistema radicular bem mais estruturado, refletindo em maior crescimento tanto em altura quanto em diâmetro do colo das mudas.

Em média, independentemente do tipo de estaca, as miniestacas apresentaram $15,3 \mathrm{~cm}$ e as microestacas, 14,3 cm de altura. De acordo com Gomes et al. (1996), as empresas florestais utilizam como adequado para mudas de eucalipto altura média em torno de 15 e 30 $\mathrm{cm}$ e diâmetro do coleto superior a $2 \mathrm{~mm}$. Os valores 
Redução foliar em miniestacas e microestacas de clones...

Tabela 1 - Sobrevivência (SOB) e raízes observadas na extremidade inferior do tubete (ROEIT) de miniestacas (Mini) e microestacas (Micro) na saída da casa de vegetação (30 dias) e da casa de sombra (40 dias), dos clones de Eucalyptus urophylla x E. globulus (C04 e C16) e Eucalyptus grandis x E. globulus (C26 e C30), em razão do tipo de estaca utilizado $(\mathrm{E} 1$ = apical com folha inteira; $\mathrm{E} 2$ = apical com folha reduzida à metade de sua dimensão original e E3 = intermediária com folha reduzida à metade de sua dimensão original).

Table 1 - Survival (SUR) and roots observed at the lower end of the tube (ROEIT) of mini-cuttings (Mini) and micro-cuttings (Micro) off the greenhouse (30 days) and the shade house (40 days) of clones of Eucalyptus urophylla $x$ E. globulus (C04 and C16) and Eucalyptus grandis $x$ E. globulus (C26 and C30), depending on the type of cutting used (E1 = apical with entire leaf, E2 = apical with leaf reduced to half of its original size, and E3 = intermediate with leaf reduced to half of its original size).

\begin{tabular}{|c|c|c|c|c|c|c|}
\hline \multirow{2}{*}{ Clone } & \multirow{2}{*}{ Técnica } & \multirow{2}{*}{ Tipo de estaca } & \multicolumn{2}{|c|}{ Casa de vegetação } & \multicolumn{2}{|c|}{ Casa de sombra } \\
\hline & & & $\mathrm{SOB}(\%)$ & ROEIT(\%) & $\mathrm{SOB}(\%)$ & ROEIT(\%) \\
\hline \multirow[t]{6}{*}{$\mathrm{C} 04$} & Mini & E 1 & $28,1 \mathrm{Bb}$ & $12,5 \mathrm{Ba}$ & $25,0 \mathrm{Bc}$ & $16,6 \mathrm{Bb}$ \\
\hline & & E2 & $56,3 \mathrm{Aa}$ & $18,8 \mathrm{Aa}$ & $41,6 \mathrm{Ab}$ & $29,2 \mathrm{Ba}$ \\
\hline & & E3 & $56,3 \mathrm{Aa}$ & $9,4 \mathrm{Aa}$ & $62,5 \mathrm{Aa}$ & $31,3 \mathrm{Aa}$ \\
\hline & Micro & E 1 & $87,5 \mathrm{Aa}$ & $21,9 \mathrm{Aa}$ & $87,5 \mathrm{Aa}$ & $62,5 \mathrm{Aa}$ \\
\hline & & E2 & $53,1 \mathrm{Ab}$ & $25,0 \mathrm{Aa}$ & $45,8 \mathrm{Ab}$ & $50,0 \mathrm{Ab}$ \\
\hline & & E3 & $51,3 \mathrm{Ab}$ & $11,5 \mathrm{Ab}$ & $58,8 \mathrm{Ab}$ & $33,3 \mathrm{Ac}$ \\
\hline \multirow[t]{6}{*}{$\mathrm{C} 16$} & Mini & $\mathrm{E} 1$ & 96,9Аа & $41,6 \mathrm{Ba}$ & 96,9Аa & $81,3 \mathrm{Aa}$ \\
\hline & & E2 & $78,1 \mathrm{Aa}$ & $46,9 \mathrm{Aa}$ & $78,1 \mathrm{Ab}$ & $62,5 \mathrm{Ab}$ \\
\hline & & E3 & $96,9 \mathrm{Aa}$ & $43,8 \mathrm{Aa}$ & $96,9 \mathrm{Aa}$ & $68,8 \mathrm{Ab}$ \\
\hline & Micro & $\mathrm{E} 1$ & $93,8 \mathrm{Aa}$ & $58,3 \mathrm{Aa}$ & $93,8 \mathrm{Aa}$ & $78,1 \mathrm{Aa}$ \\
\hline & & E2 & $75,0 \mathrm{Ab}$ & $50,0 \mathrm{Aa}$ & $71,9 \mathrm{Ab}$ & $68,8 \mathrm{Aa}$ \\
\hline & & E3 & $87,5 \mathrm{Aa}$ & $40,6 \mathrm{Ab}$ & $87,5 \mathrm{Aa}$ & $62,5 \mathrm{Ab}$ \\
\hline \multirow[t]{6}{*}{$\mathrm{C} 26$} & Mini & E 1 & $93,8 \mathrm{Aa}$ & $28,1 \mathrm{Bb}$ & $90,6 \mathrm{Aa}$ & $65,6 \mathrm{Ab}$ \\
\hline & & $\mathrm{E} 2$ & $93,8 \mathrm{Aa}$ & $53,1 \mathrm{Aa}$ & $93,8 \mathrm{Aa}$ & $87,5 \mathrm{Aa}$ \\
\hline & & E3 & $90,6 \mathrm{Aa}$ & $16,6 \mathrm{Ac}$ & $87,5 \mathrm{Aa}$ & $34,4 \mathrm{Ac}$ \\
\hline & Micro & E 1 & $100,0 \mathrm{Aa}$ & $53,1 \mathrm{Aa}$ & $93,8 \mathrm{Aa}$ & $78,1 \mathrm{Aa}$ \\
\hline & & E2 & $90,6 \mathrm{Aa}$ & $53,1 \mathrm{Aa}$ & $87,5 \mathrm{Aa}$ & $78,8 \mathrm{Aa}$ \\
\hline & & E3 & $84,4 \mathrm{Aa}$ & $21,9 \mathrm{Ab}$ & $81,3 \mathrm{Ab}$ & $34,4 \mathrm{Ab}$ \\
\hline \multirow[t]{6}{*}{$\mathrm{C} 30$} & Mini & E1 & $87,5 \mathrm{Aa}$ & $16,6 \mathrm{Bb}$ & $87,5 \mathrm{Aa}$ & $68,8 \mathrm{Aa}$ \\
\hline & & E2 & $84,4 \mathrm{Aa}$ & $37,5 \mathrm{Aa}$ & $84,4 \mathrm{Aa}$ & $66,3 \mathrm{Aa}$ \\
\hline & & E3 & $91,6 \mathrm{Aa}$ & $22,5 \mathrm{Ab}$ & $91,6 \mathrm{Aa}$ & $37,5 \mathrm{Ab}$ \\
\hline & Micro & E 1 & $87,5 \mathrm{Aa}$ & $41,6 \mathrm{Aa}$ & $78,1 \mathrm{Ab}$ & $65,6 \mathrm{Aa}$ \\
\hline & & E2 & $87,5 \mathrm{Aa}$ & $37,5 \mathrm{Aa}$ & $87,5 \mathrm{Aa}$ & $72,4 \mathrm{Aa}$ \\
\hline & & E3 & $93,8 \mathrm{Aa}$ & $25,0 \mathrm{Aa}$ & $93,8 \mathrm{Aa}$ & $43,8 \mathrm{Ab}$ \\
\hline
\end{tabular}

encontrados neste estudo provavelmente sejam devidos ao fato de o material utilizado ser mais difícil de propagar, influenciando, assim, o crescimento e desenvolvimento das mudas.

De acordo com os dados apresentados na Tabela 2, não foi verificada diferença entre as técnicas de propagação, miniestaquia e microestaquia quanto às características massa de matéria seca da parte aérea e massa de matéria seca do sistema radicular, exceto no clone $\mathrm{C} 04$, em que as microestacas apicais foram superiores às miniestacas apicais, com redução foliar para a característica massa de matéria seca de raiz. Para essa mesma característica, em relação ao tipo de estaca utilizado, os resultados indicaram que as microestacas intermediárias dos clones C04 e C16 e as miniestacas intermediárias do clone $\mathrm{C} 16$ foram inferiores às microestacas e miniestacas apicais, respectivamente. Não foi observado efeito significativo entre as estacas apicais sem redução e com redução foliar.

\section{DISCUSSÃO}

O fato de os percentuais de sobrevivência das miniestacas e microestacas se apresentarem altos na saída da casa de vegetação advém do controle das condições ambientais no interior da casa de vegetação, as quais são favoráveis à manutenção da sobrevivência dos propágulos vegetativos. O clone C04 apresentou 
Tabela 2 - Enraizamento (ENR), número de raízes (NR), altura (Alt), diâmetro de colo (DC), massa de matéria seca da parte aérea (MSPA) e massa de matéria seca do sistema radicular (MSR) de miniestacas (Mini) e microestacas (Micro) dos clones de Eucalyptus urophylla x E. globulus (C04 e C16) e de Eucalyptus grandis x E. globulus (C26 e C30) aos 90 dias, em razão do tipo de estaca utilizado (E1 = apical com folha inteira, E 2 = apical com folha reduzida à metade de sua dimensão original e E3 = intermediária com folha reduzida à metade de sua dimensão original).

Table 2 - Rooting (ROOT), number of roots (NR), height (Hei), root collar diameter (RCD), shoot dry weight (SDW) and root dry weight (RDW) of mini-cuttings (Mini) and micro-cuttings (Micro) of clones of Eucalyptus urophylla $x$ E. globulus (C04 and C16) and Eucalyptus grandis $x$ E. globulus (C26 and C30) at 90 days, depending on type of cutting used (E1 = apical with entire leaf, E2 = apical with leaf reduced to half of its original size, and E3 = intermediate with leaf reduced to half of its original size).

\begin{tabular}{|c|c|c|c|c|c|c|c|c|}
\hline \multirow{2}{*}{ Clone } & \multirow{2}{*}{ Técnica } & \multirow{2}{*}{ Estaca } & \multicolumn{6}{|c|}{ Crescimento a pleno sol } \\
\hline & & & $\operatorname{ENR}(\%)$ & NR & $\operatorname{Alt}(\mathrm{cm})$ & $\mathrm{DC}(\mathrm{mm})$ & $\operatorname{MSPA}(\mathrm{g})$ & $\operatorname{MSR}(g)$ \\
\hline \multirow[t]{6}{*}{$\mathrm{C} 04$} & \multirow[t]{3}{*}{ Mini } & E 1 & $15,6 \mathrm{Bb}$ & $3,0 \mathrm{Aa}$ & $15,8 \mathrm{Aa}$ & $2,1 \mathrm{Aa}$ & $1,0 \mathrm{Aa}$ & $0,6 \mathrm{Aa}$ \\
\hline & & E2 & $54,2 \mathrm{Aa}$ & $3,0 \mathrm{Ba}$ & $15,8 \mathrm{Aa}$ & $1,9 \mathrm{Aa}$ & $0,8 \mathrm{Aa}$ & $0,3 \mathrm{Ba}$ \\
\hline & & E3 & $25,0 \mathrm{Bb}$ & $3,7 \mathrm{Aa}$ & $11,2 \mathrm{Ab}$ & $2,1 \mathrm{Aa}$ & $0,4 \mathrm{Aa}$ & $0,6 \mathrm{Aa}$ \\
\hline & \multirow[t]{3}{*}{ Micro } & E 1 & $87,5 \mathrm{Aa}$ & $3,6 \mathrm{Aa}$ & $14,0 \mathrm{Aa}$ & $2,3 \mathrm{Aa}$ & $0,8 \mathrm{Aa}$ & $0,4 \mathrm{Ab}$ \\
\hline & & E2 & $45,6 \mathrm{Ac}$ & $5,2 \mathrm{Aa}$ & $15,7 \mathrm{Aa}$ & $2,2 \mathrm{Aa}$ & $0,9 \mathrm{Aa}$ & $0,6 \mathrm{Aa}$ \\
\hline & & E3 & $66,7 \mathrm{Ab}$ & $3,7 \mathrm{Aa}$ & $11,8 \mathrm{Ab}$ & $2,2 \mathrm{Aa}$ & $0,6 \mathrm{Aa}$ & $0,4 \mathrm{Ab}$ \\
\hline \multirow[t]{6}{*}{$\mathrm{C} 16$} & \multirow[t]{3}{*}{ Mini } & E 1 & $84,4 \mathrm{Aa}$ & $4,8 \mathrm{Ba}$ & $19,3 \mathrm{Aa}$ & $2,5 \mathrm{Aa}$ & $1,3 \mathrm{Aa}$ & $0,5 \mathrm{Aa}$ \\
\hline & & E2 & $78,1 \mathrm{Aa}$ & $5,5 \mathrm{Aa}$ & $16,8 \mathrm{Aa}$ & $2,3 \mathrm{Aa}$ & $1,1 \mathrm{Aa}$ & $0,4 \mathrm{Aa}$ \\
\hline & & E3 & $81,3 \mathrm{Aa}$ & $3,7 \mathrm{Ab}$ & $10,7 \mathrm{Ab}$ & $1,9 \mathrm{Ab}$ & $0,6 \mathrm{Ab}$ & $0,3 \mathrm{Aa}$ \\
\hline & \multirow[t]{3}{*}{ Micro } & E 1 & $93,8 \mathrm{Aa}$ & $7,0 \mathrm{Aa}$ & $17,3 \mathrm{Aa}$ & $2,2 \mathrm{Aa}$ & $1,3 \mathrm{Aa}$ & $0,5 \mathrm{Aa}$ \\
\hline & & E2 & $68,8 \mathrm{Ac}$ & $6,1 \mathrm{Aa}$ & $15,3 \mathrm{Aa}$ & $2,2 \mathrm{Aa}$ & $1,0 \mathrm{Aa}$ & $0,3 \mathrm{Aa}$ \\
\hline & & E3 & $79,2 \mathrm{Ab}$ & $4,8 \mathrm{Ab}$ & $10,7 \mathrm{Ab}$ & $1,9 \mathrm{Aa}$ & $0,5 \mathrm{Ab}$ & $0,2 \mathrm{Aa}$ \\
\hline \multirow[t]{6}{*}{$\mathrm{C} 26$} & \multirow[t]{3}{*}{ Mini } & E 1 & $79,2 \mathrm{Aa}$ & $3,4 \mathrm{Ba}$ & $19,8 \mathrm{Aa}$ & $2,2 \mathrm{Aa}$ & $0,8 \mathrm{Aa}$ & $0,3 \mathrm{Aa}$ \\
\hline & & E2 & $81,3 \mathrm{Aa}$ & $5,0 \mathrm{Aa}$ & $19,2 \mathrm{Aa}$ & $2,4 \mathrm{Aa}$ & $0,9 \mathrm{Aa}$ & $0,5 \mathrm{Aa}$ \\
\hline & & E3 & $59,4 \mathrm{Aa}$ & $3,4 \mathrm{Ba}$ & $12,3 \mathrm{Ab}$ & $2,0 \mathrm{Aa}$ & $0,5 \mathrm{Aa}$ & $0,5 \mathrm{Aa}$ \\
\hline & \multirow[t]{3}{*}{ Micro } & E 1 & $87,5 \mathrm{Aa}$ & $5,3 \mathrm{Aa}$ & $18,8 \mathrm{Aa}$ & $2,3 \mathrm{Aa}$ & $0,9 \mathrm{Aa}$ & $0,5 \mathrm{Aa}$ \\
\hline & & E2 & $78,1 \mathrm{Aa}$ & $4,8 \mathrm{Aa}$ & $16,8 \mathrm{Aa}$ & $2,2 \mathrm{Aa}$ & $0,9 \mathrm{Aa}$ & $0,5 \mathrm{Aa}$ \\
\hline & & E3 & $65,6 \mathrm{Aa}$ & $5,8 \mathrm{Aa}$ & $10,5 \mathrm{Ab}$ & $2,1 \mathrm{Aa}$ & $0,5 \mathrm{Aa}$ & $0,3 \mathrm{Aa}$ \\
\hline \multirow[t]{6}{*}{$\mathrm{C} 30$} & \multirow[t]{3}{*}{ Mini } & E 1 & $78,1 \mathrm{Aa}$ & $5,5 \mathrm{Ba}$ & $16,2 \mathrm{Aa}$ & $2,3 \mathrm{Aa}$ & $1,1 \mathrm{Aa}$ & $0,3 \mathrm{Aa}$ \\
\hline & & E2 & $75,0 \mathrm{Aa}$ & $4,1 \mathrm{Bb}$ & $15,2 \mathrm{Aa}$ & $2,0 \mathrm{Aa}$ & $0,9 \mathrm{Aa}$ & $0,3 \mathrm{Aa}$ \\
\hline & & E3 & $70,8 \mathrm{Aa}$ & $3,7 \mathrm{Ab}$ & $11,6 \mathrm{Ab}$ & $2,4 \mathrm{Aa}$ & $0,8 \mathrm{Aa}$ & $0,4 \mathrm{Aa}$ \\
\hline & \multirow[t]{3}{*}{ Micro } & E 1 & $71,9 \mathrm{Ab}$ & $7,5 \mathrm{Aa}$ & $15,8 \mathrm{Aa}$ & $2,8 \mathrm{Aa}$ & $1,3 \mathrm{Aa}$ & $0,4 \mathrm{Aa}$ \\
\hline & & E2 & $84,4 \mathrm{Aa}$ & $7,0 \mathrm{Aa}$ & $16,5 \mathrm{Aa}$ & $2,4 \mathrm{Aa}$ & $1,0 \mathrm{Aa}$ & $0,3 \mathrm{Aa}$ \\
\hline & & E3 & $68,8 \mathrm{Ab}$ & $3,9 \mathrm{Ab}$ & $9,0 \mathrm{Ab}$ & $2,2 \mathrm{Aa}$ & $0,6 \mathrm{Ab}$ & $0,2 \mathrm{Aa}$ \\
\hline
\end{tabular}

Médias seguidas de uma mesma letra minúscula, entre tipos de estacas e dentro de uma mesma técnica de propagação, e as seguidas de uma mesma letra maiúscula, entre técnicas de propagação dentro do mesmo tipo de estaca, não diferem entre si, pelo teste de Tukey a $5 \%$ de probabilidade.

baixa sobrevivência desde a saída da casa de vegetação, o que pode estar relacionado com o grau de juvenilidade e condições fisiológicas do material propagado, pois, quando se utilizaram microestacas sem corte foliar, observou-se sobrevivência similar à dos demais clones.

Apesar da elevada sobrevivência das miniestacas/ microestacas na saída da estrutura de enraizamento, ocorreu significativa mortalidade durante a fase de aclimatação em casa de sombra. Segundo Wendling e Xavier (2005) e Xavier et al. (2013), a redução do percentual de sobrevivência das miniestacas/ microestacas na fase de saída da casa de sombra pode estar relacionada a mudanças das condições ambientais, em que os efeitos de oscilações hídricas e lumínicas, ocorridas na área de aclimatação, proporcionam maiores estresses às miniestacas/ microestacas (BRONDANI et al., 2010a,b; OLIVEIRA et al., 2012).

O crescimento a pleno sol é a etapa final de formação da muda, na qual as mudas apresentam um sistema radicular desenvolvido, ocorrendo a degeneração daquelas estacas com um sistema radicular incompleto.

Revista Árvore, Viçosa-MG, v.39, n.2, p.295-304, 2015 
Dessa forma, a redução no enraizamento observada nas miniestacas e microestacas, quando transferidas para a fase de crescimento em pleno sol, indicou que muitos propágulos ainda não possuíam sistema radicular adequado que assegurasse o desenvolvimento da muda. Resultado semelhante foi verificado por Oliveira et al. (2012).

Com relação ao tipo de estaca, as miniestacas/ microestacas apicais, independentemente da área foliar, apresentaram resultados superiores às miniestacas/ microestacas intermediárias para todas as características avaliadas na saída da casa de vegetação, da casa de sombra e a pleno sol. Isso está correlacionado com a maior juvenilidade dos propágulos, havendo formação mais rápida de raízes e de mudas com o sistema radicular bem mais estruturado, refletindo em maior crescimento tanto em altura quanto em diâmetro do colo das mudas. A habilidade dos tecidos das plantas para a formação de raízes adventícias depende de diferentes fatores endógenos e exógenos e da interação entre eles. Segundo Xavier et al. (2009; 2013), a estaca apical possui grau de maturação fisiológica e de lignificação menor do que a intermediária, sendo mais propensa à formação de raízes. Acrescenta-se que as auxinas são sintetizadas, principalmente, em regiões de crescimento ativo, como gemas terminais e primórdios foliares, o que contribuiria para a elevação dos níveis endógenos desse hormônio nas estacas apicais, refletindo em maior potencial de enraizamento (RAVEN et al., 2007; HARTMANN et al., 2011; BORGES et al., 2011; OLIVEIRA et al., 2012).

As microestacas apicais apresentaram raízes em maior número, o que pode estar relacionado com a juvenilidade das estacas apicais, além de estas apresentarem menor lignificação dos tecidos, o que favoreceu o desenvolvimento das raízes.

Analisando as técnicas de propagação, observouse que não houve diferença entre miniestaquia e microestaquia, exceto no clone $\mathrm{C} 04$, em que a microestaquia foi superior à miniestaquia, demonstrando, portanto, a eficiência da micropropagação na produção de mudas de alguns genótipos com dificuldades no enraizamento adventício.

De acordo com Oliveira et al. (2012), a ausência de diferença entre miniestaquia e microestaquia nos clones $\mathrm{C} 16, \mathrm{C} 26$ e C30 pode ter sido em razão do grau de juvenilidade e vigor vegetativo apresentado pelas minicepas utilizadas, refletido diretamente no enraizamento. Além disso, é possível que o número de subcultivos, na fase de multiplicação in vitro dos clones C16, C26 e C30, não tenha sido suficiente para promover rejuvenescimento significativo dos materiais genéticos. De acordo com Xavier et al. (2009), resultados satisfatórios para o enraizamento via microestaquia de Eucalyptus têm sido obtidos após 10 e 12 subcultivos, pela micropropagação para clones de Eucalyptus urophylla, Eucalyptus grandis e seus híbridos. Entretanto, flutuações na capacidade rizogênica são capazes de ocorrer mesmo entre genótipos estritamente aparentados, podendo não refletir de maneira idêntica o rejuvenescimento promovido pela micropropagação (MANKESSI et al., 2009). Assim, material genético aparentado pode apresentar diferenças quanto à capacidade rizogênica. Resultados semelhantes foram obtidos por Oliveira et al. (2012), trabalhando com os mesmos clones híbridos de E. globulus nesse trabalho em questão.

Conforme Gomes e Paiva (2004), o diâmetro de colo é facilmente mensurável, sendo considerado importante parâmetro para estimar a sobrevivência de mudas de espécies florestais no campo. De acordo com esses autores, o padrão de qualidade de mudas de várias espécies florestais, prontas para o plantio, tem alta correlação com esse parâmetro, e isso pode ser observado nos significativos aumentos das taxas de sobrevivência e do crescimento das plantas no campo. Entretanto, neste estudo não houve efeito dos diferentes tipos de estacas utilizados influenciando o crescimento em diâmetro dos clones estudados. Os valores encontrados neste trabalho provavelmente se devem ao fato de o material utilizado ser mais difícil de ser propagado, influenciando, assim, no crescimento e desenvolvimento das mudas.

Existe relação positiva entre área foliar de miniestacas e capacidade rizogênica de eucalipto, incluindo velocidade de enraizamento, número de raízes e biomassa radicular. De acordo com Alfenas et al. (2009), o emprego de miniestacas com folhas inteiras tem demonstrado resultados promissores quanto ao aumento no enraizamento e controle de doenças, já que, nesse caso, como não é necessário fazer ferimentos nas folhas, evita-se a abertura de portas de entrada para patógenos.

Para a maioria das variáveis analisadas, os diferentes níveis de redução das folhas não afetaram o desenvolvimento destas. Assim, com base nessas variáveis, qualquer nível de redução da folha pode

Revista Árvore, Viçosa-MG, v.39, n.2, p.295-304, 2015 
ser aplicado para a produção de mudas dos clones híbridos de E. globulus. Esse resultado tem importantes implicações práticas, como redução do tempo da produção das miniestacas/microestacas, do estresse causado nas miniestacas/microestacas como resultado do corte efetuado na redução das folhas e, consequentemente, do risco de contaminação por fungos. Além disso, evitase o trabalho repetitivo pela equipe de produção das mudas, em razão da não realização do corte foliar (SANTANA et al., 2010). Esses resultados estão de acordo com os de Santana et al. (2007) e Santana et al. (2010), que também estudaram o efeito da redução da área foliar no enraizamento de clones de eucalipto.

Em algumas espécies, a presença de folhas é essencial para o enraizamento de miniestacas, devido ao fato de o processo de fotossíntese levar ao armazenamento de carboidrato que, por sua vez, favorece o crescimento das raízes (HARTMANN et al., 2011). A perda de água é uma das principais causas da morte de miniestacas antes da formação das raízes, uma vez que para a divisão celular ocorrer é necessário que as células dos tecidos das miniestacas estejam túrgidas (NOBERTO et al., 2001). A razão para a redução da folha é evitar o efeito "guarda-chuva", que pode prejudicar a eficiência da irrigação e evitar o excesso de transpiração. No entanto, neste trabalho não foi observada irrigação ineficiente devido ao efeito "guarda-chuva" e nem murchamento das folhas em decorrência da transpiração excessiva. Segundo Santana et al. (2010), a não redução da área foliar é viável devido à maior eficiência dos sistemas de irrigação, que nos últimos anos teve incremento tecnológico considerável devido à menor área foliar das miniestacas/microestacas, em comparação com as macroestacas.

\section{CONCLUSÕES}

Os materiais genéticos comportaram-se de maneira distinta em relação ao enraizamento de miniestacas e microestacas. Por sua vez, a microestaquia não apresentou resultados superiores ao da miniestaquia, à exceção do clone $\mathrm{C} 04$.

De maneira geral, as estacas apicais sem e com redução foliar foram superiores às estacas intermediárias, apresentando maior predisposição ao enraizamento. Assim, o nível de redução de $0 \%$ da folha pode ser recomendado para a produção de mudas de Eucalyptus urophylla x E. globulus de Eucalyptus grandis x E. globulus.

Revista Árvore, Viçosa-MG, v.39, n.2, p.295-304, 2015

\section{AGRADECIMENTOS}

Os autores agradecem à FAPEMIG (Fundação de Amparo à Pesquisa do Estado de Minas Gerais) pelo apoio financeiro concedido para o desenvolvimento desta pesquisa, à CAPES (Coordenadoria de Aperfeiçoamento de Pessoal de Nível Superior) pela concessão da bolsa de estudos e à Empresa Celulose Nipo-Brasileira S.A. (Cenibra) pelo fornecimento do material genético

\section{REFERÊNCIAS}

AlfEnAS, A. C.; ZAUZA, E. A. V.; MAFIA, R. G.; ASSIS, T. F. Clonagem e doenças do eucalipto. 2.ed. Viçosa, MG: Universidade Federal de Viçosa, 2009. 500p.

ASSIS, T.F.; FETT-NETO, A.G.; ALFENAS, A.C. Current techniques and prospects for the clonal propagation of hardwoods with emphasis on Eucalyptus. In: WALTER, C.; CARSON, M. (Ed.) Plantation forest biotechnology for the $21^{\text {th }}$ century. Kerala, India: Research Signpots, 2004.p.303-333.

ASSIS, T.F; ROSA, O.P.; GONÇALVES, S.I. Propagação por microestaquia. In: Congresso Florestal Estadual, 7., 1992, Nova Prata. Anais... Santa Maria: Universidade Federal de Santa Maria, 1992. p.824-836.

BORGES, S. R.; XAVIER, A.; OLIVEIRA, L. S.; MELO, L. A.; ROSADO, A. M. Enraizamento de miniestacas de clones híbridos de Eucalyptus globulus. Revista Árvore, v.35, n.3, p.425434, 2011.

BRONDANI, G. E.; GROSSI, F.; WENDLING, I.; DUTRA, L. F.; ARAUJO, M. A. Aplicação de IBA para o enraizamento de miniestacas de Eucalyptus benthamii Maiden \& Cambage $\mathrm{x}$ Eucalyptus dunnii Maiden. Acta

Scientiarum. Agronomy, v.32, n.4, p.667674, 2010a.

BRONDANI, G.E.; WENDLING, I.; GROSSI, F.; DUTRA, L.F.; ARAUJO, M.A. Miniestaquia de Eucalyptus benthamii $\times$ Eucalyptus dunnii: (ii) sobrevivência e enraizamento de miniestacas em função das coletas e estações do ano.

Ciência Florestal, v.20, n.3, p.453-465. 2010b. 
CARDoso, G. V. Otimização do cozimento kraft para produção de celulose a partir de madeiras de Eucalyptus globulus com diferentes teores de lignina. 2002. 147f. Dissertação (Mestrado em Engenharia Florestal) - Universidade Federal de Santa Maria, Santa Maria, 2002.

GOMES, J. M.; PAIVA, H. N. Viveiros

florestais - propagação sexuada. 3.ed. Viçosa, MG: Universidade Federal de Viçosa, 2004. 116p.

GOMES, J.M.; PAIVA, H.N.; COUTO, L. Produção de mudas de eucalipto. Informe

Agropecuário, v.18, n.185, p.15-22, 1996.

HARTMANN, H. T.; KESTER, D. E.; DAVIES Jr, F. T.; GENEVE, R. L. Plant propagation: principles and practices. 8.ed. New Jersey: Prentice Hall, 2011.915p.

HARTMANN, H.T.; KESTER, D.E. Plant propagation. New Jersey: Prentice-Hall, 1975. 662p.

HIGASHI, E. N.; SILVEIRA, R. L. V. A.; GONÇALVES, A. N. Propagação vegetativa de Eucalyptus: princípios básicos e sua evolução no Brasil. Piracicaba: IPEF/ ESALQ/USP, 2000. 10p. (Circular Técnica, 192).

NOBERTO, P. M.; CHALFUN, N. N. J.; PASQUAL, M.; VEIGA, R. D.; PEREIRA, G. E.; MOTA, J. H. Efeito da época de estaquia e do AIB no enraizamento de estacas de figueira (Fícuscarica L.). Ciência e Agrotecnologia, v.25, n.3, p.533-541, 2001.

OLIVEIRA, L. S.; XAVIER, A.; DIAS, P. C.; CORREIA, A. C. G.; BORGES, S. R.; TAKAHASHI, E. K.; PAIVA, H. N. Enraizamento de miniestacas e microestacas de clones de Eucalyptus urophylla x E. globulus e de Eucalyptus grandis $\mathrm{x}$ E. globulus. Scientia Forestalis, v. 40, n. 96, p. 507-516, 2012.

PINTO, G. C. C. C. Regeneração de plantas de Eucalyptus globulus por embriogênese somática. 2007. 203f. Tese (Doutorado em Biologia) - Universidade de Aveiro, Portugal, 2007.

RAVEN, P. H.; EVERT, R. F.; EICHHORN, S. E. Biologia vegetal. 7.ed. Rio de Janeiro: Guanabara Koogan, 2007. 830p.
SANTANA, R. C.; DIAS, B. A. S.; DUTRA, T. R.; NOGUEIRA, G. S.; OLIVEIRA, M. N. S.; SOUZA, C. M. P.; SILVA, M. P.; GRAZZIOTTI, P. H. Influência da área foliar na produção de matéria seca de miniestacas de eucalipto. In: CONGRESSO BRASILEIRO DE CIÊNCIA DO SOLO, 31., 2007, Gramado. Anais... Gramado: Sociedade Brasileira de Ciência do Solo, 2007. CD-ROM.

SANTANA, R. C.; DUTRA, T. R.; CARVALHO NETO, J.P.; NOGUEIRA, G.S.; GRAZZIOTTI, P.H; BARROS FILHO, N.F. Influence of leaf area reduction on clonal production of Eucalyptus seedlings. Cerne, v. 16, n.3, p.251-257, 2010.

TITON, M. Propagação clonal de Eucalyptus grandis por miniestaquia e microestaquia. 2001. 65f. Dissertação (Mestrado em Ciência Florestal) - Universidade Federal de Viçosa, Viçosa, MG, 2001.

WATT, M. P.; BERJAK, P.; MAKHATHINI, A.; BLAKEWAY, F. In vitro field collection techniques for Eucalyptus micropropagation. Plant Cell, Tissue and Organ Culture, v.75, p.233-240, 2003.

WENDLING, I.; XAVIER, A. Influência do ácido indolbutírico e da miniestaquia seriada no enraizamento e vigor de miniestacas de clones de Eucalyptus grandis. Revista Árvore, v.29, n.6, p.921-930, 2005.

WENDLING, I.; XAVIER, A.; GOMES, J.M.; PIRES, I.E.; ANDRADE, H.B. Propagação clonal de híbridos de Eucalyptusspp por miniestaquia. Revista Árvore, v.24, n.2, p.181-186, 2000.

XAVIER, A.; WENDLING, I. Miniestaquia na clonagem de Eucalyptus. Viçosa, MG: SIF, 1998. 10p. (Informativo Técnico, 11)

XAVIER, A. A.; SANFUENTES, E. V.; JUNGHANS, D. T.; ALFENAS, A. C. Resistência de Eucalyptus globulus e Eucalyptus nitens à ferrugem (Pucciniapsidii). Revista Árvore, v.31, n.4, p.731-735, 2007.

XAVIER, A.; COMÉRIO, J. Microestaquia: uma maximização da micropropagação de Eucalyptus. Revista Árvore, v.20, n.1, p.9-16, 1996.

XAVIER, A. Silvicultura clonal I: princípios e técnicas de propagação vegetativa. Viçosa, MG: Universidade Federal de Viçosa, 2002. 64p. (Caderno didático, 92)

Revista Árvore, Viçosa-MG, v.39, n.2, p.295-304, 2015 
XAVIER, A.; WENDLING, I.; SILVA, R. L.

Silvicultura clonal: princípios e técnicas.

Viçosa, MG: Universidade Federal de Viçosa, 2009. 272p.
XAVIER, A.; WENDLING, I.; SILVA, R. L.

Silvicultura clonal: princípios e técnicas. $2 \cdot \mathrm{ed}$.

Viçosa, MG: Universidade Federal de Viçosa, 2013. 272 p. 